\title{
Editorial
}

\section{Chronic Ulcers: Updating Epidemiology, Physiopathology, and Therapies}

\author{
Marco A. C. Frade ${ }^{1}$ and Pranab K. Das ${ }^{2,3}$ \\ ${ }^{1}$ Wound Healing Group, Division of Dermatology, Department of Internal Medicine, Faculty of Medicine of Ribeirão Preto, \\ University of São Paulo, 14.049-900 Ribeirão Preto, SP, Brazil \\ ${ }^{2}$ Department of Pathology (Neuropathology Unit), Academic Medical Center, University of Amsterdam (Amc-UvA), \\ Meibergdreef 9, 1105 AZ Amsterdam, The Netherlands \\ ${ }^{3}$ Division of Infection and Immunity, College of Medical and Dental Sciences, University of Birmingham, Edgbaston B15 2T, UK
}

Correspondence should be addressed to Marco A. C. Frade; mandrey@fmrp.usp.br

Received 19 May 2013; Accepted 19 May 2013

Copyright (C) 2013 M. A. C. Frade and P. K. Das. This is an open access article distributed under the Creative Commons Attribution License, which permits unrestricted use, distribution, and reproduction in any medium, provided the original work is properly cited.

I, as the Lead Guest Editor and co-editors would like to convey our sincere thanks to the Editorial Board of Ulcers, for the privilege rendered to ourselves in addressing the journal readers.

Primary goal for compiling this special issue was to encourage researchers (both clinical and non-clinical) engaged directly with care for patients suffering from with chronic leg ulcers to publish their experiences in the form of articles. Based on this goal the present edition has been compiled. We sincerely hope that it will promote an update knowledge covering the multiple angles on the topic of ulcers, which is nowadays a worldwide public health problem with high morbidity but still neglected.

Among the submitted manuscripts papers were particularly selected: (i) studies focusing on the epidemiology of risk factors for chronic ulcers, (ii) new concepts about etiology and physiopathology of leg ulcers, (iii) impaired wound healing associated with the hereditary factors, (iv) biofilm formation and bacteria resistance, (v) new methods to access osteomyelitis in diabetic foot, and so forth. Lastly, but not the least, several review articles about many other aspects of chronic ulcers have also been included in order to bring together the important knowledge about their treatment.

In the future, considering the importance of the theme "leg ulcers and healing" and the huge number of aspects related to it, the publishing of the new special issues about it should be stimulated, mainly involving experimental models, new treatments and technologies, and cell therapy.

\section{Acknowledgments}

This brief editorial has also to acknowledge our sad feeling for the death of my friend, Joaquim Coutinho-Netto, in August 2012. Dr. Coutinho was a distinguished medical doctor and associate professor at the University of São Paulo, Brazil. He published several papers on wound healing, and he was also invited to be one of our guest editors for this special issue. We hope that the readers will join me in expressing our condolence to the friends and family of Dr. Coutinho. Finally, we would like to thank the reviewers who invested their valuable time to support us and make this issue possible. Most importantly we sincerely hope that this issue will serve a useful reference for the teachers and researchers in the field of ulcers.

Marco A. C. Frade, Pranab K. Das. 


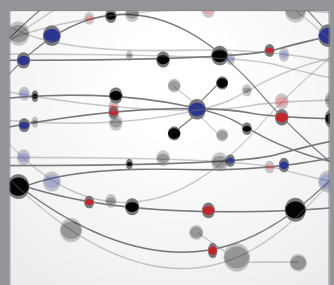

The Scientific World Journal
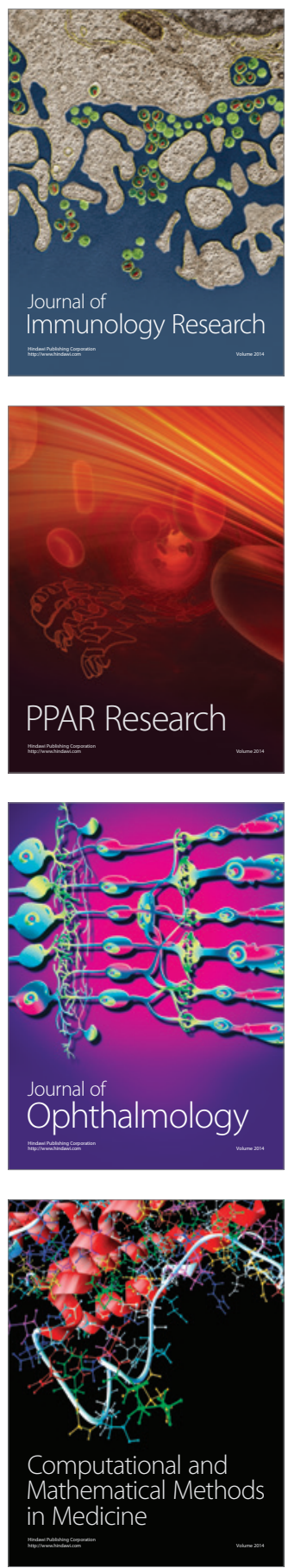

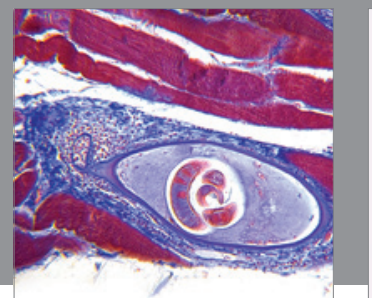

Gastroenterology

Research and Practice
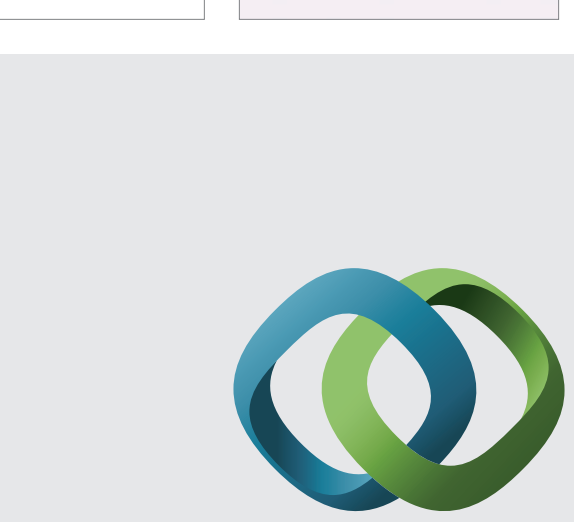

\section{Hindawi}

Submit your manuscripts at

http://www.hindawi.com
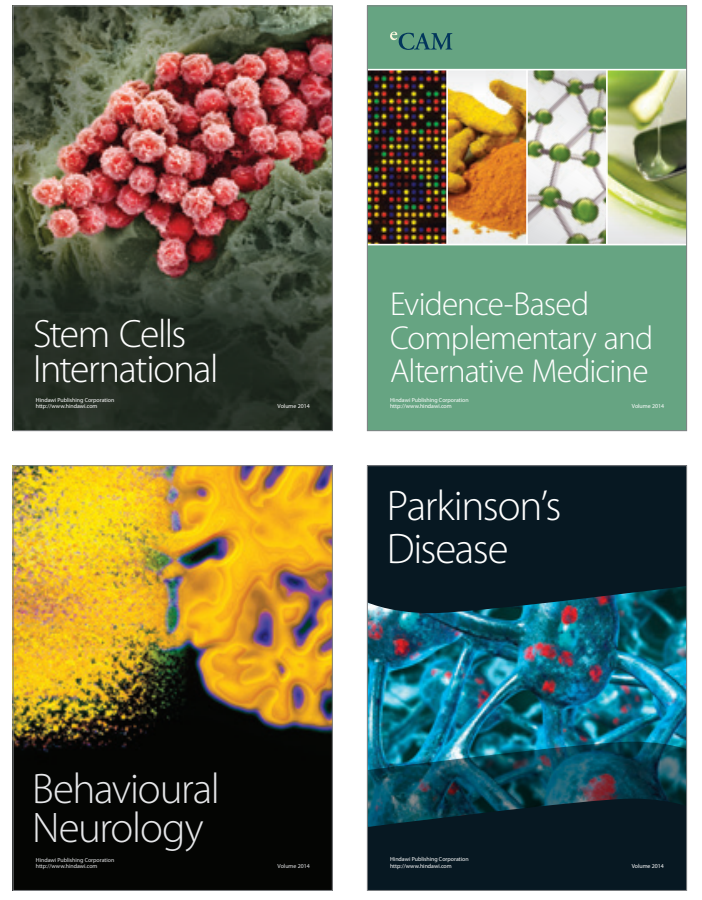
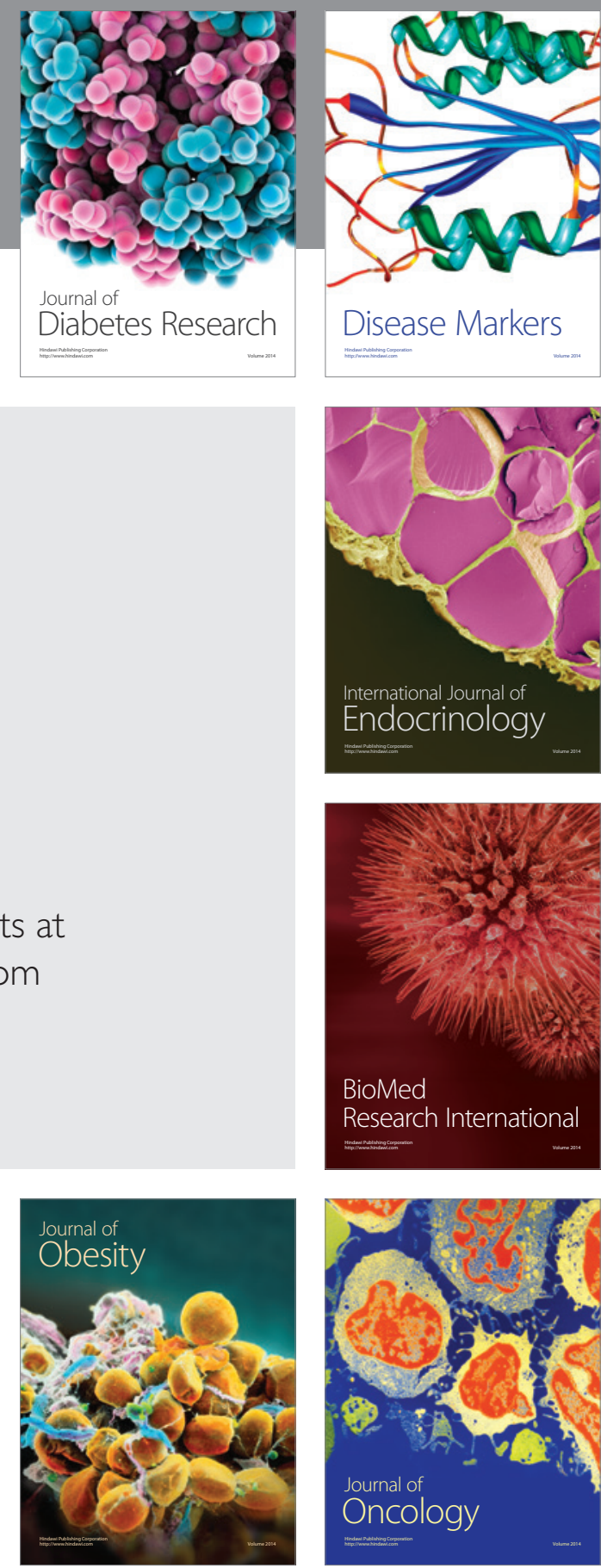

Disease Markers
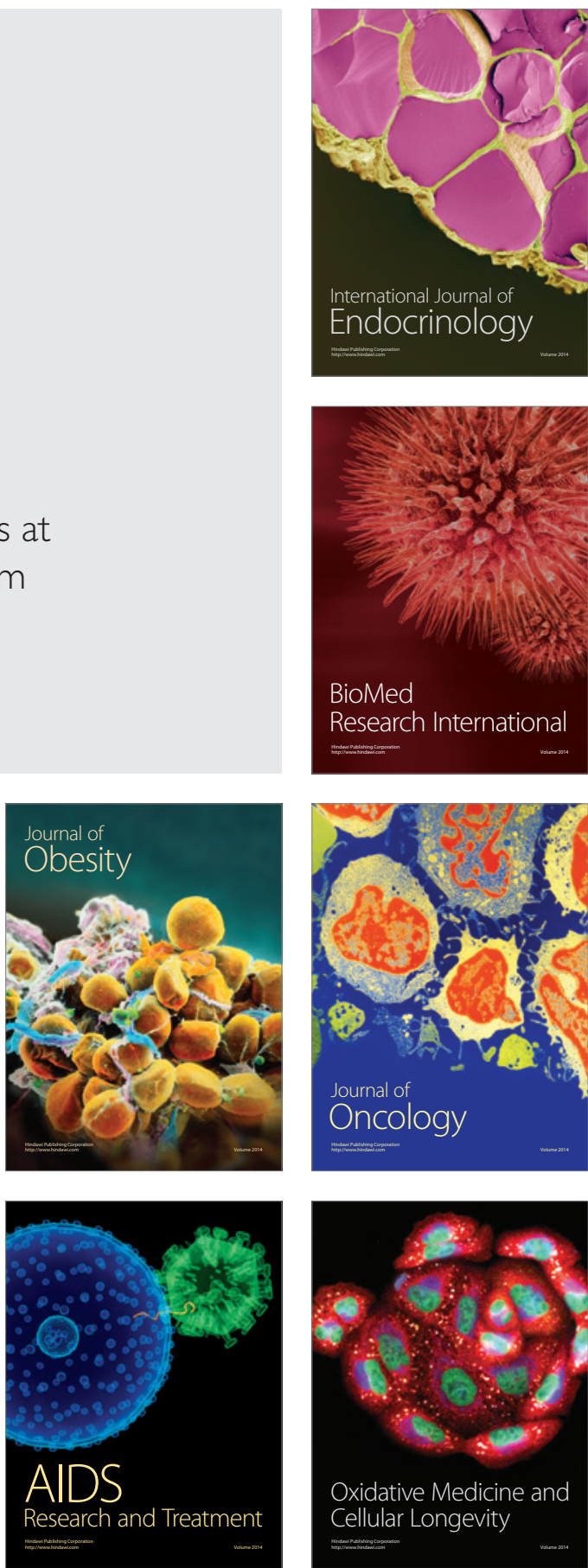